\title{
Lessons to be learned from varicella-zoster virus
}

\author{
Rentier B, Piette J, Baudoux L, Debrus S, Defechereux P, Merville M-P, Sadzot-Delvaux C,
} Schoonbroodt S.

Laboratory of Fundamental Virology and Immunology, Department of Microbiology, Institute of Pathology B23, University of Liège, B-4000 Liège, Belgium

\begin{abstract}
Varicella-zoster virus (VZV) is an alphaherpesvirus responsible for two human diseases: chicken pox and shingles. The virus has a respiratory port of entry. After two successive viremias, it reaches the skin where it causes typical lesions. There, it penetrates the peripheral nervous system and it remains latent in dorsal root ganglia. It is still debatable whether VZV persists in neurons or in satellite cells. During latency, VZV expresses a limited set of transcripts of its immediate early (IE) and early (E) genes but no protein has been detected. Mechanisms of reactivation from ganglia have not been identified. However, dysfunction of the cellular immune system appears to be involved in this process. The cell-associated nature of VZV has made it difficult to identify a temporal order of gene expression, but there appears to be a cascade mechanism as for HSV-1. The lack of high titre cell-free virions or recombination mutants has hindered so far the understanding of VZV gene functions. Five genes, ORFs 4, 10, 61, 62, and 63 that encode regulatory proteins could be involved in VZV latency. ORF4p activates gene promoters with basal activities. ORF10p seems to activate the ORF 62 promoter. ORF61p has trans-activating and trans-repressing activities. The major IE protein ORF62p, a virion component, has DNA-binding and regulatory functions, transactivates many VZV promoters and even regulates its own expression. ORF63p is a nuclear IE protein of yet unclear regulatory functions, abundantly expressed very early in infection. We have established an animal model of VZV latency in the rat nervous system, enabling us to study the expression of viral mRNA and protein expression during latency, and yielding results similar to those found in humans. This model is beginning to shed light on the molecular events in VZV persistent infection and on the regulator mechanisms that maintain the virus in a latent stage in nerve cells.
\end{abstract}

\section{Keywords}

Varicella-zoster virus; Herpesvirus; Latency; Reactivation; Neurotropism; Gene regulation

\section{The virus and its replication}

Varicella-zoster virus (VZV), belongs to the Herpesviridae family. It is closely related to other herpesviruses such as herpes simplex viruses (HSV-1 and HSV-2), cytomegalovirus (CMV) and Epstein-Barr virus (EBV), human herpesviruses 6 and 7 (HHV-6 and -7) as well as numerous animal herpesviruses (BHV-1, -2, -5, EHV-1, CapHV-1, CerHV-1, -2 and PRV). VZV belongs to the Alphaherpesvirinae subfamily like HSV-1 and -2 in human, suid herpesvirus 1 in swine (also known as pseudorabies virus, PRV) and bovine herpesvirus 1 (BHV-1) in cattle. They all share important characteristics, such as neurotropism, a rapid and highly lytic replicative cycle as well as the ability to undergo latency, particularly in the peripheral and, to a lesser extent, central nervous system and to reactivate.

Specifically human in its host range, VZV is responsible for one of the best recognized persistent viral infections in man. However, the molecular mechanisms controlling its latency in the nervous system and its reactivation remain unclear. VZV was first isolated in cultures of human embryonic fibroblasts by T.H. Weller (Weller and Stoddard, 1952; Weller, 1953), who also demonstrated that the agent responsible for chicken pox and shingles was one and the same (Weller et al., 1958). As revealed by electron microscopy, VZV cannot be distinguished from other herpesviruses. It is an enveloped virus, 180 to $200 \mathrm{~nm}$ in diameter, which does not bud at the plasma membrane of the infected cell, but at the internal membrane of the nucleus. Its capsid is icosahedral and encloses a double-stranded linear DNA wrapped around a protein structure. The space between the capsid and the envelope is filled with a 
tegument, the protein(s) of which could play a major role in the immediate triggering of viral transcription when the virus enters its target cell, by analogy with the role of $\alpha$-TIF in HSV- 1 . The viral DNA has been cloned and fully sequenced (Davison and Scott, 1986). It contains 124,884 base pairs. The genome reveals 71 open reading frames, coding for 67 proteins, of which only about one half have been identified.

The replicative cycle of VZV is classical for herpesviruses. The virus adsorbs onto target cells through specific receptors yet undetermined, although the mannose 6-phos-phate receptor and heparan sulfate could play an important role (Zhu et al., 1995). The capsid penetrates into the cell and releases the viral genome which travels to the nucleus. The cell transcribes the immediate early genes (IE), then the early genes (E). Corresponding transcripts are translated into proteins that control viral genome replication and transcription of late genes (L) coding for virus structural proteins and some non-structural proteins which will remain in the cell. The late stage of viral replication is virion assembly. Structural proteins synthesized in the cytoplasm migrate to the nucleus, assemble into capsomers then in complete capsids enclosing the viral DNA.

\section{Chicken pox}

The virus penetrates by the upper respiratory tract and infects the respiratory mucosa where it multiplies. After 4 to 6 days, the virus disseminates in the bloodstream. This primary viremia allows the virus to infect reticulo-endothelial cells. Several multiplication cycles occur there during the incubation period. A second viremia, more widespread, occurs one week later. Prodromal signs appear, then cutaneous and mucous lesions on day 14. The virus also infects other organs such as the gastrointestinal and genitourinary tracts, pleural and peritoneal membranes as well as parenchyma of nearly all organs. This secondary viremia ends after 3 days with the help of the immune system (HopeSimpson, 1965). Muscular and articular pain may precede the onset of the rash, usually accompanied by fever. Vesicles, the fluid of which is extremely rich in infectious virus, are visible during 4 days, then scab after 2 to 3 days.

Chicken pox is usually followed by a latent infection of the peripheral nervous system ganglia where the virus can reactivate many years later and provoke shingles (Hope-Simpson, 1965). Zoster is thus the result of a viral reactivation from a ganglion and not from an exogenous reinfection. Virus was found in ganglia by electron microscopy and immunofluorescence (Eisiri and Tomlinson, 1972; Nagashima et al., 1975). Later, the presence of its genome was revealed by in situ hybridization (Gilden et al., 1983; Hyman et al., 1983; Vafai et al., 1988; Croen et al., 1988). However, the state of the latent genome and the mechanism of its reactivation remain elusive. If, in vitro, HSV is easily reactivated from latently infected sensory ganglia after explanation, such a reactivation has not been conclusively described for VZV.

\section{Zoster-associated pain (ZAP)}

Very often, the zoster episode is accompanied by severe pain which can be prodromal and lasts usually a few days. Sometimes, mostly in elderly patients, pain can last much longer, from several weeks to several years. It is now generally considered that, although it is impossible for the patient to tell the difference, ZAP is composed of two distinct pains: the acute pain during the zoster episode and the persistent pain, called post-herpetic neuralgia (PHN). PHN, by far the most distressful aspect of VZV infection, occurs when the virus is apparently cleared. It could result from lesions made to neurons involved in pain or in the control of pain.

\section{Animal models}

This lack of information concerning VZV latency and reactivation results mostly from the difficulty to set up a suitable animal model which would reproduce all the characteristics of VZV infection in humans. Although guinea pigs were often used to study VZV pathogenesis after inoculation of guineapig-adapted infectious virus (Matsunaga et al., 1982; Myers et al., 1985; Walz-Cicconi et al., 1986; Myers et al., 1991), latency had not been demonstrated in these models until recently (Lowry et al., 1993). The first models of VZV latency were described in the adult rat nervous system in vitro (Merville-Louis et al., 1989) and in vivo (Sadzot-Delvaux et al., 1990, 1995b). Other experimental models of latency, such as in mice (Wroblewska et al., 1993) or in rabbits (Dunkel et al., 1995) have 
been set up lately. However, all these models reproduce only partly the various aspects of VZV infection.

\section{Neurotropism}

$\mathrm{VZV}$ is able to penetrate several cell types in vivo and it is not known whether the mechanism of cell recognition is the same for neurons and other cells. However, it is safe to assume that entry into nerve cells is mediated through the interaction between an external protein of the virion and a 'receptor' present at the surface of the target cell. Since Herpesviridae possess 7 or 8 surface glycoproteins (VZV has only 6) and several non-glycosylated transmembrane proteins, there are many candidates for such interactions. Neuron infection could also be conditioned in a later step of the infectious process, during penetration, uncoating or even later. A late gene of HSV-1 which is not necessary for growth in culture has been proposed as responsible for neurovirulence (Chou et al., 1990). Its equivalent in VZV should be looked for and, if it exists, it would thus be an interesting target for neurotropism knock out. Indeed, attenuation of VZV virulence such as in the current OKA vaccine strain does not prevent neurotropism. It would be useful to construct recombinant viruses lacking one or several proteins to identify those responsible for neurotropism. Such mutants have been developed for PRV and HSV. Because of the cell-associated nature of VZV, this approach has failed. However, there is now hope to achieve such a goal since infectious particles of VZV have been generated by transfection of human melanoma cells with overlapping cosmid clones (Cohen and Seidel, 1993). Moreover, the yield of infectious virus generated by this type of transfection was greatly improved ( 70 fold) when the purified VZV DNA was cotransfected with a plasmid expressing IE62 (Moriuchi et al., 1994a). This approach could become essential in the near future for generating recombinant VZV virions and for engineering nonneurotropic vaccine strains.

In HSV latency, it has been demonstrated that the virus remains quiescent in sensory ganglia neurons. The search for VZV components in human ganglia yielded contradictory information about the cell type in which the virus resides during latency: studies indicated the presence of viral nucleic acids exclusively in neurons (Hyman et al., 1983; Gilden et al., 1987) while in another set of experiments, viral-specific RNAs were found in non-neuronal cells surrounding the neuron (Croen et al., 1988; Croen and Straus, 1991; Meier and Straus, 1992). In the latter case, the hypothesis is that the virus remaining quiescent in non-neuronal cells is reactivated in these cells and infects other satellite cells before reaching the neurons. This is consistent with the comparative pathogenesis of herpes zoster and herpes simplex recurrences. In zoster, the virus would spread from neuron to neuron within a ganglion by replicating in the satellite cells and travel back to the skin along numerous axons, causing widespread lesions in the skin of an entire dermatome. In herpes simplex, the virus residing in a neuron would become reactivated in that neuron and travel back to the skin along one axon, causing focalized lesions in the skin (Meier and Straus, 1992).

In the in vivo model of latency that we have established in the rat (Sadzot-Delvaux et al., 1990, 1995b), we could detect VZV antigens and nucleic acids after dissociation and culture of DRG cells. In these conditions, localization was neuron-specific. However, in DRG sections, viral nucleic acids could be detected both in neuronal and non-neuronal cells. These data were obtained after a short time of infection (7 days) and they can reflect the early events of latency during which virus could infect different cell types productively before becoming quiescent. No reactivation could be observed in this system, except by explanation, repeated trypsinizations and cocultures with permissive cells.

\section{Viral gene regulation}

Unraveling the regulation of gene expression could be essential to understand the neurotropism and latency of VZV. In particular, the regulation of the very early steps of the viral cycle could be different during lytic or latent infection. Many studies have demonstrated that viral IE and E genes are transcribed during VZV latency. It seems that, in nerve cells, viral gene regulation is abnormal and progress of infection is modified or even impaired.

Five VZV genes encoding proteins with regulatory functions could be involved in the establishment and maintenance of virus latency in ganglia: open reading frames (ORFs) 4, 10, 61, 62 and 63.

\subsection{ORF 4}


VZV ORF 4 encodes a protein (ORF4p) exhibiting both structural and transcriptional regulatory functions and possibly present in the virus particle (Kinchington et al., 1995). ORF4p shares considerable amino acid sequence similarity with HSV-1 ICP27 and EHV-1 UL3. ORF 4 is transcribed as two mRNAs (1.8 and $3.0 \mathrm{~kb}$ ) with a single initiation site (Kinchington et al., 1994). Although ICP27 is essential for HSV-1 replication, the role of ORF4p is not well understood. Both have distinct regulatory properties in vitro (Inchauspe et al., 1989; Inchauspe and Ostrove, 1989; Defechereux et al., 1993) and they are unable to complement each other efficiently (Moriuchi et al., 1994b). ORF4p can activate several VZV genes on its own or in combination with ORF62p but it has no repressing activity. In fact it appears to be able to activate VZV as well as heterologous viral promoters providing they have a basal activity. Heterologous regulation by ORF4p seems to be transcriptional, but its regulation of VZV promoters could be post-transcriptional (Defechereux et al., 1993). As opposed to ICP27, ORF4p activates various promoters if they display upstream elements which mediate its transcriptional effects and this activity involves the cysteine-rich C-terminus of ORF4p (Perera et al., 1994) while the N-terminal domain of ICP27 and ORF4p are functional homologs (Moriuchi et al., 1995). Viral infection is amplified when ORF4p is expressed in cells transfected with ORF4 (Schoonbroodt et al., 1996).

\section{2. $O R F 10$}

The ORF 10-encoded protein (ORF10p), like its homolog HSV-1 VP16, is part of the virion tegument. However, its functions are not clearly identified. ORF10p is 80 amino acids shorter than VP16 at the Cterminus. Its promoter is very weak (Moriuchi et al., 1993). Even though ORF10p neither complexes with a TAATGARAT element nor with cellular proteins as opposed to VP16 (McKee et al., 1990), it trans-activates ORF 62 and HSV-1 ICP4 (Moriuchi et al., 1993). ORF10p-expressing cell lines can complement a HSV-1 VP16 mutant lacking trans-activating functions. ORF10p enhances virus productivity in these cells when transfected with HSV-1 virion DNA (Moriuchi et al., 1993). While HSV VP16 is essential for immediate trans-activation of HSV genes, VZV ORF1Op is dispensable for VZV replication in vitro (Cohen and Seidel, 1994).

\subsection{ORF 61}

The ORF 61 encoded protein (ORF61p) shares a limited amino acid sequence similarity with HSV-1 ICPO which functions as a transcriptional activator. ORF61p is present in VZV-infected cell nuclei as a heterogeneous protein phosphorylated at the N-terminal region (Stevenson et al., 1992), which contains a RING finger domain required for its transregulatory functions (Moriuchi et al., 1994c). Phosphorylation is weaker at the C-terminal region which directs transport of ORF61p to the nucleus (Stevenson et al., 1992). The regulatory functions of ORF61p are still controversial. It could repress the activity of VZV-encoded trans-activators of putative viral IE (ORF 62 and 4), E (TK), and L (gE) gene promoters, at the transcriptional level (Nagpal and Ostrove, 1991; Moriuchi et al., 1992). However, neither trans-activating nor trans-repressing activities were observed in T lymphocyte lines unless ORF61p acts in combination with ORF62p and synergizes the activation of ORF 4, ORF 61 and TK gene promoters (Perera et al., 1992a).

\subsection{ORF 62}

The ORF 62 gene product (ORF62p) is the major VZV regulatory protein and it is expressed as a nuclear IE phosphoprotein (Shiraki and Hyman, 1987). It can complement HSV ICP4-mutants of HSV1 and it is thus a functional analog of ICP4 (Felser et al., 1988; Disney and Everett, 1990). Indeed, there is a large amino acid similarity (McGeoch et al., 1986; Ostrove, 1990; Davison, 1991). ORF62p is present in large amounts in the virus tegument (Kinchington et al., 1992). It transactivates VZV gene promoters of all classes strongly and in a dose-dependent fashion and it must play a crucial role in the replication of VZV (Inchauspe et al., 1989; Inchauspe and Ostrove, 1989; Perera et al., 1992a,b). It can also either repress or activate its own promoter depending on its concentration (Disney et al., 1990; Perera et al., 1992b; Baudoux et al., 1995). Viral infection is boosted when ORF62p is expressed in cells transfected with ORF62 (Schoonbroodt et al., 1996). ORF62p has distinct functional domains: a powerful activation domain in the N-terminal region (Perera et al., 1993; Cohen et al., 1993), a domain at the border between regions 4 and 5 playing possibly a role in promoter activation and repression 
(Baudoux et al., 1995), a DNA-binding domain in region 2 (Wu and Wilcox, 1991; Tyler and Everett, 1993; Tyler et al., 1994) and a nuclear localization signal in region 3 (Baudoux et al., 1995). ORF62p activates the DNA polymerase and the major DNA binding protein genes of VZV (ORFs 28 and 29), which are juxtaposed in the genome (Meier et al., 1994). This is done bidirectionally in cooperation with a cellular protein (USF) which could prepare the common intervening promoter for the activation of ORF62p.

\subsection{ORF 63}

The ORF 63-encoded protein, ORF63p, is associated with the virion (Kinchington et al., 1995). As a true IE protein, it is found in infected cell nuclei as early as $6 \mathrm{~h}$ after infection (Debrus et al., 1995), later in the cytoplasm. Two mRNAs are transcribed from ORF 63 (1.3 and $1.9 \mathrm{~kb})$ and multiple transcription start sites have been identified but, unlike in HSV-1 IE genes, no TAATGARAT motif (Kinchington et al., 1995). Regulatory functions of ORF63p are not yet defined. It activates the VZV TK gene (ORF 36) promoter (Jackers et al., 1992), but none other (Kost et al., 1995). We found recently that ORF63p reduces the activating effect of ORF4p on the ORF 62 promoter (S. Debrus, unpublished). ORF63p is heavily expressed in rat dorsal root ganglia neurons during latency as well as in the skin of patients with early herpes zoster symptoms (Debrus et al., 1995). The role of ORF63p in latency or/and reactivation could thus be important and it is worth being further investigated. All the information mentioned above is based upon data collected in transient expression experiments in vitro. The situation must be much more complicated in cells where the various regulatory proteins interact with each other.

\section{Latency and reactivation}

Contrary to other Alphaherpesvirinae, VZV latency is not characterized by the presence of a latencyassociated transcript (LAT). Large regions of the genome are transcribed (for review, see Ref. Hay and Ruyechan, 1994), but the virus has never been reactivated ex vivo by plating the ganglia in culture. Mechanisms triggering reactivation in vivo are still unknown. In man, reactivation goes along with immunosuppression or immune dysfunction (Hata, 1980). However, the link between these phenomena is still largely hypothetical.

Transcripts of ORF 4, ORF 29, ORF 62 and ORF 63 have been found in ganglia of human cadavers with no sign of VZV reactivation at the time of death (Croen et al, 1988; Croen and Straus, 1991; Meier et al., 1993). In our rat model of VZV latency, we have also found by PCR the expression of ORF 4, ORF 29, ORF 62 and ORF 63 transcripts and in addition, we could detect ORF63p with an antiserum raised against a recombinant ORF63p expressed in procaryotes (Sadzot-Delvaux et al., 1995b; Debrus et al., 1995). Others have reported the detection in humans, by PCR, of the expression of ORF 21 and possibly ORF 10, two putative late genes (Cohrs et al., 1992, 1994). The reason for this discrepancy is not clear. It could be related to the delay before processing the samples post mortem, with a possible at least partial reactivation of the virus at the time of death.

ORFs 4, 62 and 63 are IE genes while ORF 29 is an E gene. Their expression during latency stresses the potential importance of these sequences and of the proteins they code for in the maintenance of latency, perhaps in its establishment as well, and in reactivation.

Several scenari can be proposed to explain VZV latency:

1. neurons could generate a specific factor interacting with transcription or repressing viral expression;

2. neurons could fail to generate a specific factor needed to complete the viral cycle;

3. a factor generated outside the neurons could repress viral transcription in neurons;

4. a Bel 2-like molecule could protect nerve cells from VZV-induced apoptosis.

This latter hypothesis is based on our observations that VZV induces apoptosis in infected cells and that the first cytopathic effect seen in VZV-infected cells is apoptotic. By preventing apoptosis, the neurons could in fact induce virus latency. However, the anti-apoptosis factor in this case is not the well-known proto-oncogene $\mathrm{Bel} 2$ since VZV-induced apoptosis is not Bel 2-sensitive (Sadzot-Delvaux et al., 1995a).

Another hypothesis based on antibody-induced latency by antigenic modulation, as for other enveloped persistent viruses, has been ruled out (Sadzot-Delvaux et al., 1992).

\section{Conclusions}


Although it is difficult to find in what respect the studies on VZV could teach any lesson to those studying herpesviruses of veterinary importance, a few take-home messages can be delineated.

The virus grows very poorly in culture. The first lesson is thus patience and obstinacy. There is still no complete animal model covering primary and secondary infection, neurotropism, latency and reactivation, rash and pain. These difficulties hamper considerably the advance of knowledge on VZV and its persistence. Indirect approaches had to be used through cloning and sequencing, genome and transcript probing, expression of recombinant proteins and peptide synthesis to generate specific antibodies. Neurotropism can now be monitored in an animal model (rat), raising hopes that one or several proteins will be identified as involved in virus access to the nervous system and consequently as targets for gene knock out manipulations in order to engineer new generation vaccines. Investigation has moved ahead in a manageable field: in vitro assessment of gene regulation, beginning to uncover the intimate mechanisms controlling virus replication. This new knowledge will lead hopefully to the design of drugs effective on these virus-specific pathways. Finally, the use of cosmid cloning will make it possible to work with infectious DNA and open the way for efficient large scale site-specific mutagenesis.

Finally, the most important lesson is probably to refrain from building HSV into an archetype for Alphaherpesvirinae. HSV-1 is certainly the most studied virus of the group, in part because it grows easily and abundantly in culture and because animal models have been available for a long time. However, it is becoming clear that not only its neurotropism, its latency and its reactivation are different, but also its molecular regulation. Extrapolating HSV data directly to other members of the subfamily, as we all tend to do at first, could be grossly misleading. Each virus should be studied for itself, and every piece of data must be thoroughly examined without any preconception.

\section{Acknowledgements}

JP is Research Director at the Belgian National Fund for Scientific Research (BNFSR, Brussels, Belgium). CSD was a post-doctoral Fellow of the BNFSR, then of the VZV Research Foundation (New York, USA). PD was supported by a SmithKline Beecham-BNFSR grant. LB was a grantee of 1RSIA (Brussels, Belgium), then of the Anti-Cancer Research Fund (Liege, Belgium), SD is a grantee of the IRSIA, now FRIA (Brussels, Belgium). VZV research programs in our laboratory are supported by the BNFSR, SmithKline Beecham (Rixensart, Belgium), the VZV Research Foundation and the Belgian National Lottery.

\section{References}

Baudoux, L.,, Defechereux, P., Schoonbroodt, S, Merville, M.P., Rentier, B. and Piette, J., 1995. Mutational analysis of varicella-zoster virus major immediate-early protein IE62. Nucleic Acids Res., in press. Chou, J., Kern, E.R., Whitley, RJ. and Roizman, B., 1990. Mapping of herpes simplex virus neurovirulence to $\gamma, 34.5$, a gene nonessential for growth in culture. Science, 250: 1262-1266.

Cohen, J.I. and Seidel, K.E., 1993. Varicella-zoster virus (VZV) open reading frame 10, the homolog of the essential herpes simplex virus protein VP16, is dispensable for replication in vitro. Proc. Natl. Acad. Sci.USA. 90: 7376-7380.

Cohen, J.I. and Seidel, K.E., 1994. Generation of varicella-zoster virus (VZV) and viral mutants from cosmidDNAs: VZV thymidylate synthetase is not essential for VZV replication in vitro. J. Virol., 68: $7850-7858$.

Cohen, J.I., Heffel, D. and Seidel, K., 1993. The transcriptional activation domain of varicella-zoster virus open reading frame 62 protein is not conserved with its herpes simplex virus homolog. J. Virol.. 67: 4246-4251.

Cohrs, R.J.. Mahalingham, R., Dueland, A.N., Wolf, W., Wellish. M. and Gilden, D.H., 1992.

Restricted transcription of VZV in latently-infected human trigeminal and thoracic ganglia. J, Infect. Dis., 166: S24-S29.

Cohrs, U.S., Srock, K., Barbour, M.B., Owens, G., Mahalingharn, R., Devlin, M.E., Wellish, M. and 
Gilden D.H.. 1994. Varicella-zoster virus (VZV) transcription during latency in human ganglia: Construction of a cDNA library from latently infected human trigeminal ganglia and detection of a VZV transcript. J. Virol., 68: 7900-7908.

Croen, K.D., Ostrove, J.M., Dragovic, L.J. and Straus, S.E., 1988. Patterns of gene expression and sites of latency in human nerve ganglia are different for varicella-zoster and herpes simplex viruses. Proc. Natl. Acad. Sci. USA, 85: 9773-9777.

Croen, K.D. and Straus, S.E., 1991. Varicella-zoster virus latency. Ann. Rev. Microbiol., 45: 265-282.

Davison, A.J., 1991. Varicella-zoster virus. J. Gen. Virol., 72: 475-486. Davison, A.J. and Scott, J.E., 1986. The complete DNA sequence of Varicella-zoster virus. J. Gen. Virol., 67: 1759-1816.

Debrus, S., Sadzot-Delvaux, C, Nikkels, A., Piette, J. and Rentier, B., 1995. Varicella-zoster virus open reading frame 63 encodes an immediate-early protein which is abundantly expressed during latency, $\mathrm{J}$. Virol., 69: 3240-3245.

Defechereux, P., Melen, L., Baudoux, L., Merville-Louis, M.P., Rentier, B. and Piette, J., 1993. Characterization of the regulatory functions of varicella-zoster virus open reading frame 4 gene product. J. Virol., 67:4379-4385.

Disney, G.H. and Everett, R.D., 1990. A herpes simplex type 1 recombinant with both copies of the Vmwl75 coding sequences replaced by the homologous varicella-zoster virus open reading frame. J. Gen. Virol., 71: 897-906.

Disney, G.H., Mc Kee, T.A., Preston, CM. and Everett, R.D., 1990. The product of varicella-zoster virus gene 62 autoregulates its own promoter. J. Gen. Virol., 71: 2999-3003.

Dunkel, E.C., Geary, P.A.. Pavan-Langston, D., Piatak, M. and Zhu, Q., 1995. Varicella-zoster ocular infection in the rabbit: A model of human zoster ophthalmicus. Neurology, in press.

Eisiri, M.M. and Tomlinson, A.H., 1972. Herpes zoster: Demonstration of virus in trigeminal nerve and ganglion by immunofluorescence and electron microscopy. J. Neurol. Sci., 15: 35-48.

Felser, J.M., Kinchington, P.R., Inchauspe, G., Straus, S.E. and Ostrove, J.M., 1988. Cell lines containing varicella-zoster virus open reading frame 62 and expressing the 'IE' 175 protein complement ICP4 mutants of herpes simplex virus type 1. J. Virol., 62: 2076-2082.

Gilden, D.H., Vafai, A., Shtram, Y., Becker, Y., Devlin, M. and Wellish, M., 1983. Varicella-zoster virus DNA in human sensory ganglia. Nature, 306: 478-480.

Gilden, D.H., Rozenman, Y., Murray, R., Devlin, M. and Vafai, A., 1987. Detection of varicella-zoster virus nucleic acid in neurons of normal human thoracic ganglia. Ann. Neurol., 22: 377-380.

Hata, S., 1980. Skin test with varicella-zoster virus antigen on herpes zoster patients. Arch. Dermatol. Res., 268: 65-70.

Hay, J. and Ruyechan, W.T., 1994. Varicella-zoster virus: A different kind of herpesvirus latency? Semin. Virol., 5: 241-248.

Hyman, R.W., Ecker, J.R. and Tenser, R.B., 1983. Varicella-zoster virus RNA in human trigeminal ganglia. Lancet, ii: 814-816.

Hope-Simpson, R.E., 1965. The nature of herpes zoster: A long term study and a new hypothesis. Proc. R. Soc. Med., 58: 59. Inchauspe, G., Nagpal, S. and Ostrove, J., 1989. Mapping of two varicella-zoster virus-encoded genes that activate the expression of viral early and late genes. Virology, 173: 700-709.

Inchauspe, G. and Ostrove, J., 1989. Differential regulation by varicella-zoster virus (VZV) and herpes simplex virus type-1 trans-activating genes. Virology, 173: 710-714. 
Jackers, P., Defechereux, P., Baudoux, L., Lambert, C, Massaer, M., Merville-Louis, M.P., Rentier, B. and Piette, J., 1992. Characterization of regulatory functions of the varicella-zoster virus gene 63encoded protein. J. Virol., 66: 3899-3903.

Kinchington, P.R., Hougland, J.K., Arvin, A.M., Ruyechan, W.T. and Hay J., 1992. The varicellazoster virus immediate-early protein IE62 is a major component of virus particles. J. Virol., 66: 359366.

Kinchington, P.R., Vergnes, J.P., Defechereux, P., Piette, J. and Turse, S.E., 1994. Transcriptional mapping of the varicella-zoster virus regulatory genes encoding open reading frames 4 and 63 . J. Virol., 68: 3570-3581.

Kinchington, P.R., Bookey, D. and Turse, S.E., 1995. The transcriptional regulatory proteins encoded by Varicella-Zoster open reading frames (ORFs) 4 and 63, but not ORF 61, are associated with purified virus particles. J. Virol., 69: 4274-4282.

Kost, R.G., Kupinsky, H. and Straus, S.E., 1995. Varicella-Zoster Virus gene 63: Transcript mapping and regulatory activity. Virology, 209: 218-224.

Lowry, P.W., Sabella, C, Koropchak, CM., Watson, B.N., Thackray, H.M., Abbruzzi, G.M. and Arvin, A.M., 1993. Investigation of the pathogenesis of varicella-zoster virus infection in guinea pigs by using polymerase chain reaction. J. Infect. Dis., 167: 78-83.

Matsunaga, Y., Yamanishi, K. and Takahashi, M., 1982. Experimental infection and immune response of guinea pigs with varicella-zoster virus. Infect. Immun., 37: 407-412.

McGeoch, D.J., Dolan, A., Donald, S. and Braver, D.H.K., 1986. Complete DNA sequence of the short repeat region in the genome of herpes simplex virus type 1. Nucleic Acids Res., 14: 1727-1745.

McKee, T.A., Disney, G.H., Everett, R.D. and Preston, CM., 1990. Control of expression of the varicella-zoster virus major immediate early gene. J. Gen. Virol., 71: 897-906.

Meier, J.L. and Straus, S.E., 1992. Comparative biology of latent Varicella-Zoster virus and Herpes simplex virus infections. J. Infect. Dis., 166: S13-S23.

Meier, J.L., Holman, R.P., Croen, K.D., Smialek, J.E. and Straus, S.E., 1993. VZV transcripts in human trigeminal ganglia. Virology, 193: 193-200.

Meier, J.L., Luo, X., Sawadogo, M. and Straus, S.E., 1994. The cellular transcription factor USF cooperates with varicella-zoster virus immediate-early protein 62 to symmetrically activate a bidirectional viral promoter. Mol. Cell. Biol., 14: 6896-6906.

Merville-Louis, M.P., Sadzot-Delvaux, C, Delree, P., Piette, J., Moonen, G. and Rentier, B., 1989. Varicella-zoster virus infection of adult rat sensory neurons in vitro. J. Virol., 63: 3155-3160.

Moriuchi, H., Moriuchi, M., Smith, H.A., Straus, S.E. and Cohen, J.I., 1992. Varicella-zoster virus open reading frame 61 protein is functionally homologous to herpes simplex virus type 1 ICPO. J. Virol., 66: 7303-7308.

Moriuchi, H., Moriuchi, M., Straus, S.E. and Cohen, J.I., 1993. Varicella-zoster virus open reading frame 10 protein, the herpes simplex virus VP16 homolog, transactivates herpesvirus immediate-early gene promoters. J. Virol., 67: 2739-2746.

Moriuchi, M,, Moriuchi, H., Straus, S.E. and Cohen, J.I., 1994a. Varicella-zoster virus (VZV) virionassociated transactivator open reading frame 62 protein enhances the infectivity of VZV DNA. Virology, 200:297-300.

Moriuchi, H., Moriuchi, M., Smith, H.A. and Cohen, J.I., 1994b. Varicella-zoster open reading frame 4 protein is functionally distinct from and does not complement its herpes simplex virus type 1 homolog ICP27. J. Virol., 68: 1987-1992. 
Moriuchi, H., Moriuchi, M. and Cohen, J.I., 1994c. The RING finger domain of the varicella-zoster virus open reading frame 61 protein is required for its transregulatory functions. Virology, 205: 238246.

Moriuchi, M., Moriuchi, H., Debrus, S., Piette, J. and Cohen, J.I., 1995. The acidic amino-terminal domain of varicella-zoster virus open reading frame 4 protein is required for transactivation and can functionally replace the corresponding domain of herpes simplex virus ICP27. Virology, 208: 376-382.

Myers, M.G., Stanberry, L.R. and Edmond, B.J., 1985. Varicella-zoster virus infection of strain 2 guinea pigs. J. Infect: Dis., 151: 106-113.

Myers, M.G., Connelly, B.L. and Stanberry, L.R., 1991. Varicella in hairless guinea pigs. J. Infect. Dis., 163: 746-751.

Nagashirna, K., Nagasawa, M. and Endo, H., 1975. Pathology of the human spinal ganglia in varicellazoster virus infection. Acta Neuropathol., 33: 105-117.

Nagpal, S. and Ostrove, J.M., 1991. Characterization of a potent varicella-zoster virus-encoded transrepressor. J. Virol., 65: 5289-5296.

Ostrove, J.M., 1990. Molecular biology of varicella-zoster virus. Adv. Virus Res., 38: 45-98.

Perera, L.P., Mosca, J.D., Ruyechan, W.T. and Hay, J., 1992a. Regulation of varicella-zoster virus gene expression in human T lymphocytes. J. Virol., 66: 5298-5304.

Perera, L.P., Mosca, J.D., Sadeghi-Adeh, M., Ruyechan, W.T. and Hay, J., 1992b. The varicella-zoster virus immediate early protein IE62 can positively regulate its cognate promoter. Virology, 191: 346354.

Perera, L.P., Mosca, J.D., Ruyechan, W.T., Hayward, G.S., Straus, S.E. and Hay, J., 1993. A major transactivator of varicella-zoster virus, the immediate-early protein IE62, contains a potent N-terminal activation domain. J. Virol., 67: 4474-4483

. Perera, L.P., Kaushal, S., Kinchington, P.R., Mosca, J.D., Hayward, G.S. and Straus, S.E., 1994. Varicella-zoster virus open reading frame 4 encodes a transcriptional activator that is functionally distinct from that of herpes simplex virus homolog ICP27. J. Virol., 68: 2468—2477.

Sadzot-Delvaux, C, Merville-Louis, M.P., Delree, P., Marc, P., Piette, J., Moonen, G. and Rentier, B., 1990. In vivo model for Varicella-Zoster virus persistent infection of dorsal root ganglia. J. Neurosci. Res., 26:83-89.

Sadzot-Delvaux, C, Marc, Ph., Lebon, L., Merville-Louis, M.P., Piette, J. and Rentier, B., 1992. Antibodies to varicella-zoster virus modulate antigen distribution but fail to induce viral persistence in vitro. J. Virol., 66: 7499-7504.

Sadzot-Delvaux, C, Thonard, P., Schoonbroodt, S., Piette, J. and Rentier, B., 1995a. Varicella-zoster virus (VZV) induces apoptosis in cell culture. J. Gen. Virol., in press.

Sadzot-Delvaux, C, Debrus, S., Nikkels, A., Piette, J. and Rentier, B., 1995b. Characterization of an in vivo model of VZV latency in the rat nervous system. Neurology, in press.

Schoonbroodt, S., Piette, J., Baudoux, L., Defechereux, P., Rentier, B. and Merville, M.P. Enhancement of Varicella-zoster virus infection in cell lines expressing ORF4 and ORF62 encoded proteins. J. Gen. Virol., in press.

Shiraki, K. and Hyman, R.W., 1987. The immediate early proteins of varicella-zoster virus. Virology, 156: $423-426$. 
Stevenson, D., Colman, K.L. and Davison, A.J., 1992. Characterization of the varicella-zoster virus gene 61 protein. J. Gen. Virol., 73: 521-530.

Tyler, J.K. and Everett, R.D., 1993. The DNA binding domain of the varicella-zoster virus gene 62 protein interacts with multiple sequences which are similar to the binding site of the related protein of herpes simplex virus type 1. Nucleic Acids Res., 21: 513-522.

Tyler, J.K., Allen, K.E. and Everett, R.D., 1994. Mutation of a single lysine residue severely impairs the DNA recognition and regulatory functions of the VZV gene 62 transactivator protein. Nucleic Acids Res., 22: 270-278.

Vafai, A., Murray, R.S., Wellish, M., Devlin, M. and Gilden, D.H., 1988. Expression of varicellazoster virus in normal human trigeminal ganglia. Proc. Natl. Acad. Sci. USA, 85: 2362-2366.

Walz-Cicconi, M.A., Rose, R.M., Dammin, G.J. and Weller, T.H., 1986. Inoculation of guinea pigs with varicella-zoster virus via the respiratory route. Arch. Virol., 88: 265-277.

Weller, T.H. and Stoddard, M.B., 1952. Intranuclear inclusion bodies in cultures of human tissue inoculated with varicella vesicle fluid. J. Immunol., 68: 311-319.

Weller, T.H., 1953. Serial propagation in vitro of agents producing inclusion bodies derived from varicella and herpes zoster. Proc. Soc. Exp. Biol. Med., 83: 340-346.

Weller, T.H., Witton, H.M. and Bell, E.J., 1958. The etiologic agents of varicella and herpes zoster: Isolation, propagation and cultural characteristics in vitro. J. Exp. Med., 108: 843-868.

Wroblewska, Z., Valyi-Nagy, T., Otte, J., Dillner, A., Jackson, A., Sole, D.P. and Fraser, N.W., 1993. A mouse model for varicella-zoster virus latency. Microb. Pathol., 15: 141-151.

Wu, C.L, and Wilcox, K.W., 1991. The conserved DNA-binding domains encoded by the herpes simplex virus type 1 ICP4, pseudorabies virus IE 180, and varicella-zoster virus ORF 62 genes recognizes similar sites in the corresponding promoters. J. Virol., 65: 1149-1159.

Zhu, Z., Gershon, M.D., Ambron, R., Gabel, C. and Gershon, A.A., 1995. Infection of cells by varicella-zoster virus: Inhibition of viral entry by mannose $\theta$-phosphate and heparin. Proc. Natl. Acad. Sci. USA, 92: 3546-3550. 